\title{
A participação social na atuação dos conselhos municipais de Bertioga - SP
}

\section{Social participation in the Bertioga - SP municipal council's actions}

Lucia Helena Presoto

Coordenadora pedagógica do Curso de Pós-Graduação Lato Sensu em Saúde Pública - Instituto Nacional de Estudos em Saúde

- INES/SP. Mestre em Saúde Pública pela Faculdade de Saúde Pública/USP

E-mail: presoto®uol.com.br

Márcia Faria Westphal

Professora Titular do Departamento de Prática de Saúde Pública da Faculdade de Saúde Pública/USP

E-mail: marciafwळusp.br

\section{Resumo}

Após a promulgação da Constituição Federal de 1988, os conselhos das áreas sociais se evidenciaram como instrumentos habilitadores no processo de descentralização das políticas sociais no âmbito local, abrindo possibilidades de participação política e superando as modalidades tradicionais vigentes até então. $\mathrm{O}$ objetivo deste trabalho foi o de identificar a composição dos Conselhos Setoriais do Município de Bertioga/SP, sua forma de atuação e analisar a participação da sociedade civil, utilizando-se a metodologia de estudo de caso na linha qualitativa. Os resultados mostraram que, embora o tempo transcorrido a partir das leis que os institucionalizaram seja curto para esperar resultados sedimentados, as conquistas e os obstáculos, na prática, sinalizam uma fragilidade, indicando a necessidade de capacitar seus membros e criar mecanismos para integrá-los, a partir da ação coletiva, para exercer influência sobre o sistema político.

Palavras-chave: Conselhos municipais; Controle social formal; Participação social. 
Abstract

After the establishment of the Federal Constitution of 1988 the councils on social areas were evidenced as enabling instruments in the process of decentralization of social policies at the local level, opening opportunities for the political participation and standing out in relation to the traditional modalities in force until then. The aim of this work was to identify the composition of Bertioga Sector Councils, their form of action and analyze the participation of the civil society, using the case study methodology in the qualitative line. The results showed that even though the time frame from their foundation up to the present is short to show concrete results, the achievements and the obstacles, in practice, point out a fragility, indicating the need of training on the part of their members as well as the creation of mechanisms to integrate them, based on collective action, if they are to have any influence over the political system.

Keywords: Municipal Councils; Formal Controls; Social participation.

\section{Introdução}

A crescente complexidade da problemática das questões sociais que afetam a saúde humana, como desemprego, falta de moradia, exclusão e violência, exige a busca de soluções múltiplas, porém integradas (Lalonde, 1996) .

Para lidar com estas diversidades, uma das propostas da Promoção de Saúde, a estratégia de "Municípios/Cidades Saudáveis", constitui um processo que tem como um dos objetivos a operacionalização de nova forma de gestão municipal, envolvendo a formulação de políticas públicas voltadas para a melhoria da qualidade de vida das pessoas. Pressupõe-se que isso ocorra num território onde as autoridades locais se relacionem com a população apoiadas nos princípios de participação social, intersetorialidade, eqüidade e sustentabilidade. A participação, nesta estratégia, precisa ser vista como um encontro de categorias sociais, classes e grupos de interesse com a perspectiva de partilhar o processo decisório, superando os conflitos através da negociação. Desta forma, cabe ao Estado buscar envolver, cada vez mais e de forma direta, os cidadãos na produção e/ou gerenciamento dos serviços públicos (РАHO 1999).

Atendendo a esta nova ordem, no Brasil, depois da promulgação da Constituição de 1988 e das leis que regulamentaram suas determinações, institucionalizaram-se novas instâncias de participação dentro do aparelho do Estado - os conselhos paritários nos diferentes níveis de governo, principal objeto de análise deste estudo.

\section{A Participação Social: conceitos}

Definir participação não é tarefa fácil por se tratar de uma ação com diferentes interpretações. De acordo com a época e a conjuntura histórica, ela aparece associada a vários termos como democracia, representação, organização, conscientização, cidadania, entre outros.

Os diferentes olhares dos autores expressam diversos aspectos desse conceito rico e complexo. Ammann (1978) a define, de forma ampla, como o processo onde as diversas camadas sociais tomam parte na gestão, produção e usufruto dos bens de uma sociedade, focalizando-a na sua dimensão mais ampla. 
Demo (1988) entende participação como uma conquista, diferente de concessão ou algo preexistente; focaliza a dimensão processual, chamando atenção para o fato da cidadania dever ser estudada sob a ótica do conflito em função de interesses diversos de diferentes grupos.

Um outro conceito, apresentado por Valla (1993), defende a institucionalização da participação popular nos órgãos e serviços do Estado. Para ele, a participação é o instrumento de governo mais adequado para construir um regime democrático e o Estado deve "criar um conjunto de mecanismos participativos", visando a incorporação dos cidadãos aos programas de governo local. A participação em Conselhos Setoriais Municipais pode ser incluída nesta abordagem conceitual de Valla, que não descarta a questão do conflito de interesses. Assim, o autor alerta para uma contradição nesta forma de participação, que, de um lado legitima a política do Estado diante da população e, de outro, significa um canal para as entidades populares disputarem o controle e a destinação da verba pública.

Boschi (1987) chama atenção para o fato destes movimentos caracterizados pela ação coletiva deverem se desenvolver fora dos canais existentes (partidos políticos e sindicatos) de acesso ao Estado, para se tornarem sujeitos coletivos que forjam uma identidade ou pressionam por novas e mais amplas formas de participação.

Entretanto, Telles (1994) acredita que mecanismos mais flexíveis e menos formais, uma "nova institucionalidade", têm sido criados pelas organizações sociais com procedimentos e regras próprias, podendo ser revisadas e renovadas de forma democrática a partir da reflexão sobre a ação. Também denominada participação cidadã, esta nova forma utiliza não apenas mecanismos institucionais disponíveis ou a serem criados, mas os articula com outros mecanismos e canais legitimados pelo processo social, cabendo ao Estado apenas estabelecer regras para lidar com o corporativismo e os particularismos, chamando atenção para a necessidade de se requalificar a participação popular nos termos da participação cidadã que interfere, interage e influencia na construção de um senso de ordem pública regida pelos critérios da eqüidade e da justiça.
Os movimentos sociais destacam a participação de um conjunto de atores distintos dando significado político às suas lutas e mobilizações. Sua atuação revela a resistência diante da tentativa de controle, historicamente exercida pelo Governo. Inicialmente, em sua maioria, estes movimentos eram de caráter reivindicatório, onde um grupo se unia para lutar por benefícios próprios ou do bairro. Para Touraine (1973) eram de caráter defensivo e contestatório, porém muitos deles tomaram outra dimensão ao incorporar o espírito da luta pela cidadania. Embora a relação do Estado com a sociedade civil, a princípio, ocorresse num espaço de enfrentamento, o propósito e o caminho trilhado tiveram um sentido de interação, articulando o desenvolvimento com o bem-estar social.

\section{A Participação em Conselhos Setoriais Governa- mentais: histórico e constituição}

A essência da participação reside na possibilidade dos usuários opinarem e participarem efetivamente na implantação e gestão dos serviços públicos dos quais são beneficiados.

Em resposta a estas necessidades, a legislação brasileira prevê, desde a Constituição de 1988, a criação de órgãos colegiados - os Conselhos Federais, Estaduais e Municipais das áreas sociais.

A participação da sociedade civil organizada em conselhos permite o exercício do controle social sobre as políticas governamentais, a formulação e proposição de diretrizes, o estabelecimento de meios e prioridades de atuação voltadas para o atendimento das necessidades e interesses dos diversos segmentos sociais, a avaliação das ações e a negociação do direcionamento dos recursos financeiros existentes.

0 tema participação perpassa a história da sociedade humana. A partir das sociedades familiares, a humanidade passou por várias fases de organização como as hordas e tribos, estados primitivos de organização incipiente até a concepção moderna de Estado.

Na Grécia, a participação era restrita a alguns grupos da sociedade, e as decisões importantes, sujeitas apenas aos cidadãos. Consideravam-se cidadãos aqueles com plena liberdade de direitos civis, contrapondose aos escravos. Os romanos avançaram um pouco mais no concernente à participação social, principalmente nas questões de direito e cidadania (CAmpos 1988). 
A revolução francesa e a industrial inglesa no século XVIII foram decisivas para a ascensão da burguesia, marcando o fim do feudalismo, dando, ao mesmo tempo, uma relevância para a questão dos direitos e criando condições para um aprofundamento dos desníveis sociais. Até a Igreja Católica, durante longo tempo ligada ao poder monárquico, abriu os olhos para a nova ordem, culminando com a Encíclica Rerum Novarum do Papa Leão XIII, editada no fim do século XIX, uma das sementes do Estado Subsidiário (CAmpos 1988).

No Brasil, os regimes políticos até a década de 1930 resultaram de uma aliança das oligarquias rurais apoiadas por setores do clero católico tradicional. O clientelismo político desenvolveu-se neste período sob a forma de troca de favores e proteções administrativas por políticos locais. A incipiente industrialização de algumas cidades se fez baseada na mão-deobra imigrante, antes destinada à agricultura. Movimentos operários, porta de entrada para a participação, começaram neste período sua organização na defesa de seus direitos sociais e da regulamentação do trabalho assalariado. (Westphal, 1992).

Embora o governo Getúlio Vargas tenha sido um regime totalitário somente superado pela ditadura militar, caracterizou-se por ter promovido avanços substanciais em termos de legislação trabalhista, garantindo direitos de cidadania "regulada" à população inserida no mercado de trabalho (Campos, 1988).

A industrialização provocou o aguçamento das contradições econômicas e sociais no meio rural; os camponeses intensificaram suas manifestações a favor da reforma agrária avolumando conflitos entre latifundiários e posseiros. As conquistas sociais foram revestidas com o cunho de regulação e o Estado concedeu "benefícios" passíveis de cobrança em véspera de eleições. Este tipo de atuação do Estado e das lideranças, ao abrir espaços para o controle dos movimentos operários, marcaram as reivindicações sociais da época (Westphal, 1992).

Entre a segunda guerra mundial e a década de 1960, o País foi palco dos regimes populistas baseados na política de negociações entre líderes políticos e massas populares, acendendo a chama social pelo voto e sua existência no meio urbano, eleito, agora, como espaço fundamental dos projetos nacionaldesenvolvimentistas. Este período gerou reformas constitucionais e administrativas, intensa disputa político-partidária entre dezenas de partidos, políticas sindicais atreladas aos governos e o surgimento dos movimentos de base em âmbito dos bairros e do trabalho da Igreja.

O Estado em crise, o desperdício e a burocratização do sistema partidário não conseguiam dar resposta às demandas da sociedade. Isto somado ao agravamento dos conflitos sociais e à crescente conscientização de vários segmentos sociais propiciaram o surgimento de novas alternativas de participação. Neste momento nasceram novos atores sociais e políticos, lutando não só pelos seus interesses, mas pela construção e efetivação de direitos e de uma cultura política de respeito às liberdades, à eqüidade social e à transparência das ações do Estado (Westphal. 1992).

No inicio dos anos de 1980, o Brasil viveu a difícil transição de um período autoritário. O Estado reconhece, sob pressão da sociedade civil, a necessidade de um processo de abertura política. Acadêmicos, cientistas e tecnocratas progressistas debatiam em seminários e congressos as endemias e a degradação da qualidade de vida da população. Esta discussão tomou força com movimentos populares como associação de moradores, de mulheres, sindicatos, igrejas e partidos políticos, que exigiam soluções para os problemas de saúde criados por este regime (Luz, 1991).

Na década de 1990, a participação foi ampliada e institucionalizada, no sentido explicitado por Valla (1993) e Boschi (1987), em diversos setores no âmbito das democracias representativas.

Ainda nos anos 9o, o mundo intensificou o processo de globalização, assumindo gradativamente características agrupadas em dois grandes conjuntos: a difusão social da produção, caracterizada pela descentralização da produção através da transnacionalização da produção (fábrica difusa), e a fragmentação geográfica e social do processo de trabalho, que resultaram numa certa desindustrialização dos países centrais e industrialização ou re-industrialização dos países periféricos, obrigando a uma reestruturação das empresas e, conseqüentemente, a um novo modelo de organização social do trabalho que caracterizou o segundo grupo - o isolamento político das classes trabalhadoras na produção, marcada pelo trabalho temporário, subcontratação, feminilização da força de 
trabalho, entre outros. Estes fatores produziram fragmentação e heterogeneização dos segmentos inseridos no processo produtivo, além de terem facilitado a emergência de novos sujeitos sociais e novas práticas de mobilização intermediadas pelas organizações não- governamentais - as ONGs.

As modificações introduzidas pela descentralização e municipalização das políticas sociais nas áreas de saúde, educação e assistência social, principalmente nos últimos anos, têm provocado novos desafios nas gestões locais (Mendes, 2002).

No setor saúde, a "Participação da Comunidade" no concernente ao Estado passa a ser um dos princípios orientadores do Sistema Único de Saúde - SUS, constituindo para sua concretização novos canais criados pela Constituição - conselhos e conferências. As Conferências Nacionais subseqüentes à VIII Conferência, marco da participação da sociedade civil, trouxeram à tona questões relacionadas à participação e suas dificuldades no controle social.

A proposta de uma nova estratégia, "Promoção da Saúde”, resgata a concepção de saúde como produção social e busca desenvolver políticas públicas e ações de âmbito coletivo que extrapolem inclusive o enfoque do risco e sejam capazes de atuar sobre os determinantes da doença de uma forma mais abrangente. Suas estratégias objetivam incidir sobre as condições de vida da população, supondo ações intersetoriais que envolvam educação, saneamento básico, habitação, renda, trabalho, alimentação, meio ambiente, lazer, acesso a bens e a serviços essenciais. Fundamenta-se em um conceito integral de saúde, com base nos determinantes sociais, privilegiando a participação social como estratégia prioritária no processo de tomada de decisão (Sicoli, 2003).

Reforçadas pelas diretrizes da Promoção da Saúde, que entendem a participação social como um dos pilares para a sustentabilidade e a eficiência de qualquer programa governamental, outras propostas têm sido desenvolvidas, como a dos Municípios/Cidades saudáveis. Na América Latina e particularmente no Brasil, por influência da Organização Pan-Americana de Saúde - OPAS e com apoio de universidades e outras instituições nacionais, constitui uma das alternativas para gestão participativa.

Para a Organização Mundial de Saúde - OMS, cidade saudável é aquela em que as autoridades políticas e civis, as instituições públicas e privadas, os empresários, os trabalhadores e a sociedade dedicam esforços constantes para melhorar as condições de vida, trabalho e cultura da população, estabelecem uma relação harmoniosa com o meio ambiente, além de expandirem os recursos comunitários para melhorar a convivência, desenvolver a solidariedade, a co-gestão e a democracia (Ferraz 1993, citado por Pelicioni 2000).

Neste cenário, este estudo se propõe a descrever e analisar a estrutura e funcionamento dos Conselhos Setoriais Municipais de Bertioga, por serem formas institucionalizadas de articulação popular e por representarem a possibilidade de unir as iniciativas que apóiam a estratégia de Municípios/Cidades Saudáveis. Pressupõe-se que a participação da sociedade civil seja organizada em conselhos capazes de permitir, por meio do exercício do controle social sobre as políticas governamentais, a formulação e a proposição de diretrizes e estratégias, além do estabelecimento de formas e prioridades de atuação voltadas para o atendimento das necessidades e interesses dos diversos segmentos sociais, avaliando ações e o direcionamento dos recursos financeiros existentes.

\section{Os Conselhos Setoriais Municipais}

No Brasil, nas últimas décadas, destacaram-se algumas experiências colegiadas "conselheiristas", como os Conselhos Comunitários, criados para atuar junto à administração municipal ao final dos anos 70; os Conselhos Populares, também nos anos 70 e parte dos anos 8o, e os Conselhos Gestores institucionalizados, principais objetos de análise deste trabalho (Gohn, 1990).

Os Conselhos Gestores Municipais são diferentes dos Conselhos Comunitários, Populares ou dos fóruns civis não-governamentais porque estes são compostos exclusivamente de representantes da sociedade civil, cujo poder reside na força da mobilização e da pressão e não possuem assento institucional no Poder Público. Os Conselhos Gestores Municipais são diferentes, também, daqueles existentes nas esferas públicas do passado, compostos exclusivamente por especialistas, com o objetivo de assessoria à administração pública. A nova versão se apresenta como um canal paritário de expressão, representação e participação, constituído por gestores e representantes da sociedade civil. Em tese, são dotados de potencial de trans- 
formação política e, se efetivamente representativos, poderão imprimir um novo formato às políticas sociais, pois se relacionam com o processo de formação das políticas e de tomada de decisões (Gohn, 2001).

Os primeiros Conselhos Setoriais Municipais criados foram na área da saúde a partir de 1991, evidenciando a tendência de vínculo com a Lei Orgânica da Saúde 8.142/9o e a Norma Operacional Básica - NOB 91/93/96, que iniciaram a normatização e operacionalização do SUS e da participação como princípio básico. Entretanto, a Norma Operacional de Assistência Social - NOAS/20oo foi fundamental para a consolidação desta participação. A Lei Orgânica de Assistência Social - LOAS 8.742/93 normatizou a participação em termos de assistência social ao tornar obrigatória a criação dos Conselhos de Assistência Social. Outras leis complementaram estas medidas: a Lei 8.o69/ 90 - Estatuto da Criança e Adolescente - ECA, que criou o Conselho Municipal da Criança e Adolescente CMDCA; e a Lei 9.394/96 - Lei de Diretrizes e Bases LDB, que criou os Conselhos da Educação, entre outros (Moreira, 2002).

A partir de 1996, a legislação brasileira vinculou o recebimento de recursos destinados às áreas sociais dos municípios à criação dos seus Conselhos, explicando porque a maioria surgiu após esta data (Gohn, 2002).

Este artigo apresenta parte de um estudo de caso realizado em Bertioga que teve como objetivo descrever as percepções dos conselheiros das áreas sociais, instituídos por leis municipais. A pesquisa buscou identificar a composição, organização e a atuação dos conselhos deste município, a participação da sociedade civil e seu grau de envolvimento com os mesmos.

Bertioga é um município do litoral norte de São Paulo, com 30.619 habitantes, podendo chegar a 350.000 nos períodos de temporada de verão. A cidade chama atenção pelo patrimônio ambiental, com uma área de $482 \mathrm{~km}^{2}$, sendo 80\% dele, território de preservação ambiental regional e nacional (IBGE, 200o). O Projeto Bertioga Município Saudável tem procurado redirecionar as estratégias locais de desenvolvimento com a participação da população tendo em vista a eqüidade e a melhoria da qualidade de vida da população local.

\section{Metodologia}

O reconhecimento da importância para este estudo de dados objetivos sobre a legislação que legitima a existência de conselhos, e a mediação por eles representada entre estas e a realidade para a qual deve apresentar soluções, orientou o estudo para a metodologia de estudo de caso, que permite analisar e relacionar, seqüencialmente, dois aspectos de uma mesma realidade (Ludke, 1986)

Foram utilizados dois instrumentos de observação: a análise documental da legislação municipal que normatiza e orienta a ação dos conselhos de Bertioga/ SP, e entrevista a vinte e oito conselheiros dos sete conselhos das áreas sociais com roteiros semi-estruturados. A amostra foi proporcional e intencional, sendo escolhidos quatro representantes de cada conselho, de forma paritária (governo e a sociedade civil), atendendo aos pressupostos conceituais da pesquisa.

Os dados obtidos pela análise documental serviram como referencial para a análise qualitativa e temática das respostas das entrevistas. A percepção dos conselheiros sobre sua atividade foi analisada através do conteúdo do discurso por temas e frases representativas apresentadas a seguir, sempre comparativamente e com base no referencial legal e na participação, conforme conceitos citados.

\section{Resultados e Discussão}

Tomando-se por base as entrevistas dos conselheiros realizadas num âmbito mais amplo, neste artigo foram priorizados os seguintes temas: identificação $e$ papel dos conselhos, papel dos conselheiros, forma de ingresso nos conselhos, função dos representantes da sociedade civil, relação estabelecida com o grupo que representa e dificuldades para participar no conselho.

Quanto à identificação, foram estudados os Conselhos Municipal de Habitação - CMH, Conselho Municipal de Meio Ambiente - CONDEMA, Conselho Municipal de Assistência Social - CMAS, Conselho Municipal do Idoso - CMI, Conselho Municipal da Criança e do Adolescente - CMDCA, Conselho Municipal da Educação - CME e Conselho Municipal de Saúde - CMS.

Papel dos conselhos: embora as funções estejam explicitadas em lei e confirmadas nos Regimentos, na 
prática, percebe-se que os papéis consultivo, deliberativo e fiscalizador se confundem no entendimento de seus conselheiros. Porém, a única função cumprida, segundo os entrevistados, é a fiscalizadora, com exceção dos CMH e CONDEMA, que possuem poder para deliberar ou interditar obras, atuando como órgão controlador na sua pasta.

A maioria dos entrevistados entende ser função do conselho fiscalizar, e não se sentem comprometidos com as soluções, atribuindo esta responsabilidade ao governo local. Isto se explica, talvez, pelo fato dos movimentos sociais terem começado com caráter reivindicador, fiscalizador e pouco propositivo e, embora esse direcionamento tenha mudado nas últimas décadas, na prática, foram encontradas respostas como: "fiscalização das verbas", "o cumprimento das propostas", "andamentos das ações", "atuação da pasta correspondente àquele conselho e da administração pública”.

Estas funções compõem o papel do conselho concomitantemente, e não de forma isolada. Na literatura há autores, como Borja (200o) citado por Gohn (2002 - p. 13), que entendem de duas maneiras o papel dos conselhos: o de articulação da sociedade civil na discussão de estratégias de gestão pública, de uma forma geral, e, em particular, na formulação de políticas públicas.

Papel dos conselheiros: As respostas exemplificam o distanciamento da maioria dos conselheiros entrevistados da sua função entendida como exercício de cidadania. As distorções encontradas estão entre aqueles que disseram exercer a função de presidente. As seguintes falas exemplificam as respostas dadas neste sentido: "minha função é ser presidente, não interfiro nas discussões, sou apenas um mediador"; "substituo o presidente nas suas ausências".

Há, ainda, aqueles que acreditam ser sua função apenas representar a Prefeitura. A maioria dos que pensam assim são conselheiros por determinação do chefe daquela pasta. Segundo eles, não estariam neste cargo se tivessem outra opção, e quando perguntados sobre seu papel, responderam: "Faço relatórios das reuniões à prefeitura"; "informo sobre a função ou assuntos da pasta para os conselheiros, esclareço o funcionamento ou forneço dados daquela pasta (secretaria) de interesse do conselho"; "não dou opinião, sou neutra, apenas represento a prefeitura".
Outro tipo de distorção foi expressa por aqueles que disseram "não ter função", assim expressando o significado da sua participação: "Eu atrapalho o conselho porque não tenho tempo, já pedi para sair, mas eles não têm ninguém para me substituir"; "o conselho não tem objetivo definido e sendo assim não tem como a gente contribuir".

Há, porém, aqueles que corporificam seu papel como contribuição para o cumprimento da função no conselho. Os representantes desta categoria disseram: "participo porque quero contribuir para o desenvolvimento sustentável da cidade"; "contribuo esclarecendo as dúvidas dos conselheiros sobre ofuncionamento da secretaria que represento". Alguns entrevistados mostram uma percepção próxima do seu papel ao afirmar ser sua função "lutar pelos interesses da classe que representam". Aqueles que entendem o papel dos conselhos nesta perspectiva mais coletiva, como social, são minoria.

Para Calderon (2000), cabe aos conselhos participar da formulação de políticas públicas, da definição dos objetivos e prioridades do governo municipal, da estruturação de meios para atingi-los, do controle e avaliação do processo. Pelo que foi demonstrado até agora e mesmo pelo que tem sido comprovado por pesquisas, os conselheiros não conhecem suas funções definidas pela legislação e por isso as competências estabelecidas nos regimentos não têm se efetivado na prática.

Forma de ingresso nos conselhos: os requisitos e critérios de escolha dos conselheiros variam de acordo com a lei específica que define o campo de atuação dos conselhos e as peculiaridades locais e regionais (Moreira, 2002).

Nesta questão pode ser observado que a maioria dos entrevistados ingressou no conselho por indicação das suas entidades de classe, não considerando a necessidade de eleição ou interesse pessoal em participar. Estes dados chamam a atenção para o risco de uma manipulação do governo local na indicação dos representantes nos conselhos de Bertioga. A eleição dos conselheiros ao invés de seguir um processo mais democrático e transparente, acaba se transformando num instrumento de negociação política.

Dificuldades para participar no conselho: as principais dificuldades apresentadas pelos conselheiros foram de natureza política. A primeira delas se refere 
ao acesso ao poder público, definida pelos entrevistados como: "falta de disponibilidade para ser atendido pelos representantes do governo"; "morosidadenos despachos das solicitações"; "falta de interesse por parte do governo"; "interferência política negativa". A segunda se refere à indicação de conselheiros, funcionários públicos, como representantes da sociedade civil, pelo poder público, expressos como: "represália por ser funcionário da Prefeitura"; "vinculo com a prefeitura"

Porém, mesmo com estas restrições, a participação se efetiva e isto pode ser observado na fala daqueles que participam porque acreditam estar defendendo uma causa, segundo eles: "o assunto diz respeito a minha área de atuação ou formação acadêmica"; "porque tenho vontade de participar"; "porque acho importante estar a par da legislação vigente sobre a área que trabalho"; "inicialmente, me colocaram aqui, mas agora eu acredito na causa".

Outro tipo de dificuldade reiterada por eles foram problemas de ordem pessoal como: "Falta de tempo"; e questões de baixa auto-estima e capacidade de participar em grupos de trabalho, expressas como: "dificuldade em ser ouvida dentro do Conselho"; "há discriminação da elite com os demais". Uma outra dificuldade para funcionamento dos conselhos apresentada pelos entrevistados está atrelada à falta de compromisso da população. Para eles, a população "desconhece o papel do Conselho"; "não tem interesse em participar"; "descompromisso como cidadão, entende que só o governo tem deveres"; "briga apenas por interesse pessoal"; "administro conflitos entre diferentes interesses".

Outra barreira se relaciona com a infra-estrutura, organização e outros recursos para funcionamento dos conselhos. Assim se expressaram os entrevistados: "Falta de infra-estrutura - local das reuniões, material de escritório, forma de divulgação"; "deficiência na comunicação interna e externa"; "forma de convocação inadequada"; "falta de estímulo porque as reuniões não têm objetividade".

As respostas dos entrevistados que alegaram não terem nenhum tipo de dificuldade foram as seguintes: "Não sinto cobrança por parte da prefeitura"; "não somos pressionados a fazer nada"; "cumprimos as datas marcadas para reunião e a pauta”.

A questão da infra-estrutura é uma discussão repetida com freqüência nos trabalhos desta área.
Martins (200o) reafirma a importância da mobilização de diferentes segmentos da sociedade civil para defender e promover os direitos da pessoa humana em suas múltiplas dimensões. No entanto, o Estado e o Governo podem e devem colaborar nessa tarefa, tendo agilidade e presteza no diálogo com todos os segmentos, e disponibilizando recursos humanos e materiais para atender às demandas legítimas decorrentes dessa mobilização.

Função dos representantes da sociedade civil: a maioria dos entrevistados entende que seu papel é trazer reivindicações da população e expressaram isto dizendo que sua função nos conselhos é: "trabalhar em conjunto com a prefeitura para contribuir para uma sociedade melhor e um município melhor"; "dar melhor assistência à população carente"; "buscar soluções para as necessidades da população carente".

Um número significativo de pessoas entende que a população "não tem representatividade", ou melhor, não sabem o que é ser representante de algum segmento social, conforme entendimento da teoria política (Benevides, 1991). Os entrevistados justificaram a falta de compromisso, explicando ser conselheiro somente para colaborar com o Governo na legitimação do mesmo para o recebimento das verbas, via Conselho, e assim se expressaram: "apenas represento a instituição que me indicou, faço anotações das reuniões e presto conta quando me perguntam" (seja governo ou sociedade civil); "não troco nenhum tipo de informação com eles, apenas faço relatórios do que acontece nas reuniões para a Prefeitura"; "forneço informações sobre os assuntos da pasta que interessam ao conselho".

Alguns conselheiros se manifestaram dizendo que a população faz parte do conselho, mas na realidade não tem capacidade para isso, porque lhe falta conhecimento técnico para discutir os assuntos da pauta, como saúde, educação, orçamento e outros.

Segundo Westphal (1992), um dos grandes problemas da participação é a representatividade. "Muitos representantes de organizações ou movimentos comparecem ao órgão colegiado sem consultar suas bases, falando em seu nome e não em nome do grupo e tão pouco compartilham as decisões tomadas nas reuniões com eles”. Estes representantes são alvos fáceis da cooptação e tutela, o que compromete a legitimidade do seu papel. 
A maioria dos entrevistados disse não perceber legitimidade no desempenho da função dos representantes, alegando: "fui jogada naquele conselho, não entendo deste assunto"; "fui indicada para participar"; "apenas repasso relatórios para prefeitura"; "não discutimos isso na nossa entidade, ninguém pergunta o que está acontecendo no conselho"; "eu represento uma classe que não existe".

Todavia, há aqueles que acreditam haver "algum tipo de representatividade". Algumas formas de captação dessas demandas foram expressas pelos entrevistados da forma a seguir: "discutimos com a classe os assuntos a serem levados para o conselho"; "através de relatórios de tudo que acontece no conselho"; "nas reuniões da nossa entidade recolho as queixas".

Autores como Boschi (1987) e Jacobi (1989) chamam atenção para avaliações realizadas até o momento sobre estes organismos de participação diante do Estado. Segundo eles, é importante ter consciência do poder e das limitações destes movimentos, pois, embora tenham conseguido impor mudanças de atitude mesmo a administradores distantes dos interesses populares, a abrangência de suas ações tem se limitado a questões conjunturais, consideradas por muitos estudiosos impotentes para impor modificações gerais às políticas sociais, não tirando seu mérito como conquista de espaço público, embora necessite ser melhor avaliado e explorado como canal de participação.

Relação estabelecida com a entidade que representa: Pela primeira vez na história existe uma legislação para garantir a participação efetiva da sociedade. Porém, nos conselhos setoriais de Bertioga se percebe um envolvimento e comprometimento da população nas decisões de forma incipiente, porque as reivindicações são elaboradas de modo genérico, mostrando que os conselheiros não entendem claramente o papel do conselho nem a sua função nele.

Martins (2000) aponta a informação e a articulação entre seus membros e entidades como a principal ferramenta para atingir o objetivo, sobretudo, daqueles que representam o Governo, de modo que as ações superem a fragmentação. Os conselhos, ao nascerem setorizados para atenderem às necessidades de cada área ficam ainda mais frágeis, pois não constituem um todo capaz de ações coletivas.

\section{Considerações Finais}

Embora sejam consideradas práticas e objetivas as idéias dos autores citados, no que se refere à eficácia dos conselhos é necessária uma reflexão para reestruturação interna e a conscientização da sua real proposta e as possibilidades de articulação.

Nos municípios sem tradição organizativa-associativa, os conselhos têm sido apenas uma realidade jurídico-formal e, muitas vezes, um instrumento a mais nas mãos dos prefeitos e das elites falando em nome da comunidade, como seus representantes oficiais, não atendendo minimamente aos objetivos de controle e fiscalização dos negócios políticos (Gohn, 2002).

Deve-se pensar na articulação dos conselhos para se fortalecerem mutuamente para negociação com a esfera política de Bertioga. Para isso umas das principais tarefas é o investimento na formação de seus integrantes de forma participativa e crítica. Entre os aspectos apresentados pela pesquisa se destacaram pontos como a necessidade de melhor compreender a relação entre o Estado e a sociedade civil, conhecer o papel dos conselhos e de seus conselheiros e a desburocratização do aparelho público para, a partir disso, desenvolver um trabalho interdisciplinar e intersetorial, no qual a qualidade de vida deve ser considerada um critério fundamental para a formulação das políticas públicas. Só assim poder-se-á caminhar para a construção de uma nova realidade na transformação da sociedade.

\section{Referências}

AMMANN, S. B. Participação social. São Paulo: Cortez e Moraes, 1978.

BENEVIDES, M. V. M. A cidadania ativa. São Paulo: Ática, 1991.

BOSCHI, R. R. A arte da associação: política de base e democracia no Brasil. Trad. de M. A. S. Ramos. São Paulo: Revistas dos Tribunais, 1987.

CALDERON, A. I. Democracia local e participação popular: a lei orgânica paulista e os novos mecanismos de participação popular em questão. São Paulo: Cortez, 2000. 
CAMPOS, J. Q. Saúde em concordata. São Paulo: LTR, 1988.

DEMO, P. Participação é conquista. São Paulo: Cortez, 1988.

GOHN, M. G. Conselhos gestores e participação popular. Serviço Social e Sociedade, São Paulo, v. 9, n. 26, p.25-47, 1990.

GOHN, M. G. Conselhos gestores e participação sociopolítica. São Paulo: Cortez, 2001.

GOHN, M. G. Papel dos conselhos gestores na gestão pública. Informativo Cepam, São Paulo, v. 1, n. 3, p. 7-15, mar. 2002.

JACOBI, P. Movimentos sociais e políticas públicas. São Paulo: Cortez, 1989.

LALONDE, M. O conceito de "campo da saúde": uma perspectiva canadense. In: ORGANIZAÇÃO PANAMERICANA DE SAÚDE. Promoção de saúde: uma antologia. Washington, DC, 1996. (Publicação científica, 557)

LÜDKE, M; ANDRÉ, M. E. D. A. Pesquisa em educação: abordagens qualitativas. São Paulo: EPU, 1986.

LUZ, M. T. Notas sobre as políticas de saúde no Brasil de "transição democrática" anos 8o. Revista de Saúde Coletiva, São Paulo, v. 1, n. 1, 1991.

MARTINS, M. H. B. Conselhos da cidadania. Informativo Cepam, São Paulo, v. 1, n. 1, Maio 2000.

MENDES, A. N. Gestão descentralizada das políticas sociais e a democracia local. Informativo Cepam, São Paulo, v. 1, n. 3, p. 17-20, mar. 2002.
MOREIRA, M. T. V. Instância deliberativa das políticas públicas de cunho social: contorno jurídico dos conselhos. Informativo Cepam, São Paulo, v. 1, n. 3, p.20-26, mar. 2002.

PAN AMERICAN HEALTH ORGANIZATION. The healthy municipalities movement: a setting approach and strategy for health promotion in Latin American and the Caribe. (draft). Washington (DC), 1999.

PELICIONI, M. C. F. Educação em saúde e educação ambiental: estratégias de construção da escola promotora da saúde. São Paulo; 20oo. Tese (Livredocência em Saúde Pública) - Faculdade de Saúde Pública, Universidade de São Paulo.

SICCOLI, J. L.; NASCIMENTO, P. R. Promoção de saúde: concepção, princípios e operacionalização. Interface - Comunicação, Saúde, Educação, Botucatu, v. 7, n. 12, p. 101-22, 2003.

TELLES, V. Sociedade civil, direitos e espaços públicos. In: VILLA-BÔAS, R. (Org.). Participação popularnos governos locais. São Paulo: Polis, 1994. v.14, p. 43-53.

TOURAINE, A. Production de la societé. Paris: Seuil, 1973.

VALLA, V. V.; STOTZ, E. M. Participação popular, educação, saúde teoria e prática. Rio de Janeiro: Relume-dumará, 1993.

WESTPHAL, M. F. Participação popular e políticas municipais de saúde: Cotia e Vargem Grande Paulista. São Paulo, 1992. Tese (Livre docência em Saúde Pública) - Faculdade de Saúde Pública, Universidade de São Paulo.

Recebido em: 29/06/2004

Aprovado em: 14/08/2004 